\title{
Comparative Study between Alvarado Scoring System and Ohmann Score as a Diagnostic Tool for Acute Appendicitis at two Teaching Centers Study in Baghdad City
}

\author{
Saddam Ali Abbas ${ }^{1}$, Haider I. Alneime², Baidaa Najm Obeed ${ }^{3}$ \\ ${ }^{I}$ Instructor Surgical Dep., College of Medicine, Ibn Sina University of Medical and Pharmaceutical Sciences, \\ Iraq, Baghdad, ${ }^{2}$ Specialist in Surgery/Surgical Department at Baghdad Teaching Hospital/Medical City Complex, \\ Iraq, Baghdad, ${ }^{3}$ Instructor Community Medicine Dep., College of Medicine, Ibn Sina University of Medical and \\ Pharmaceutical Sciences, Iraq, Baghdad
}

\begin{abstract}
Background: Acute Appendicitis first characterized as a surgical entity in 1886 by pathologist Reginald Fitz, appendicitis is now the most common abdominal emergency and appendectomy is the non-elective surgery most frequently performed by general surgeons. More than 250,000 cases are diagnosed and intervened annually in the United States. It occurs less frequently in men than in women, with a lifetime risk of $8.6 \%$ and $6.7 \%$ respectively. Acute appendicitis occurs infrequently in very young children as well as in older adults. Having its peak incidence in patients between the end of the second decade and the third decade of life. Showing an inverse relationship between incidence and mortality, its prevalence was less than $1 \%$ in the general population and increases to $4-8 \%$ in older adults.
\end{abstract}

Aim of the Study: To assess Alvarado scoring system as a diagnostic tool for acute appendicitis

Method: A prospective cross-sectional study carried at Al-Yarmouk Teaching hospital and Baghdad Teaching hospital in the period from the first of Jan 2020 to end of July 2020, in which 190 patients from both genders were enrolled, and their ages ranged from 12-68 years.

Conclusion: Alvarado score was better than Ohmann score in diagnosis of the patients with acute.

Keyword: Acute appendicitis, Alvarado score,Ohman score.

\section{Introduction}

Acute appendicitis were first characterized as a surgical entity in 1886 by pathologist Reginald Fitz ${ }^{(1)}$, appendicitis is now the most common abdominal emergency and appendectomy is the non-elective surgery most frequently performed by general surgeons ${ }^{(2)}$.

\section{Corresponding Author:}

\section{Dr. Saddam Ali Abbas}

Instructor Surgical Dep., College of Medicine, Ibn Sina University of Medical and Pharmaceutical Sciences, Iraq, Baghdad

e-mail: saddamabbas2020@gmail.com

Phone Number: +9647722059779
Annually more than 250,000 cases are diagnosed and intervened in the United States ${ }^{(3)}$. It occurs less frequently in men $(8.6 \%)$ than in women $(6.7 \%)$, with a lifetime risk of presenting it ${ }^{(4)}$.

Acute appendicitis occurs infrequently in very young children as well as in older adults, having its peak incidence in patients between the end of the second decade and the third decade of life. Showing an inverse relationship between incidence and mortality, since the latter is less than $1 \%$ in the general population and increases to $4-8 \%$ in older adults ${ }^{(5)}$.

Anatomical Considerations:

Embryology: The vermi form appendix is derived 
from the midgut along with the small intestine, the cecum, the ascending colon, and the right half of the transverse colon; all these structures in turn supplied by the superior mesenteric artery.

It is visible in the eighth week of gestation and the first accumulations of lymphatic tissue develop during the fourteenth and fifteenth weeks of gestation ${ }^{(6)}$.

Anatomy: The appendix in the adult is blind tubular in shape, approximately $9 \mathrm{~cm}$ in length, varying from short forms of $5 \mathrm{~cm}$ up to long forms of $35 \mathrm{~cm}$. The appendix has a small mesentery that contains the appendicular artery in its free edge, in this mesentery the typical arches of intestinal irrigation do not appear, so the appendicular artery is terminal, this fact may overlap the clinical environment, since being part From a terminal irrigation, the appendicular artery in cases of appendicitis is unable to supply the tissue needs, generating ischemic damage. The base of the appendix also receives blood supply from the anterior and posterior colic arteries, hence the importance of proper ligation of the appendix stump, in order to avoid bleeding from these vessels ${ }^{(7)}$. The appendicular artery is usually described as a branch of the ileocolic artery.

Clinical Diagnosis: Despite the multiple diagnostic method currently available, the clinical history focused on the evolution of pain and associated symptoms as well as the findings obtained during the physical examination are still the cornerstones of the diagnosis of appendicitis.

Historically, pain is described as acute onset and initially localized at the epigastric or periumbilical level, later with the passage of time the pain migrates to the right iliac fossa where it increases in intensity, however this only occurs in $50-60 \%$ of patients ${ }^{(8)}$.

It is important to take into account anatomical considerations and their variants since they largely influence the presentation of pain, for example with an appendix in a retrocecal location, the pain can start in the right iliac fossa or in the right flank, in the same way an appendix length beyond the midline can cause pain in the left lower quadrant ${ }^{(9)}$.

Anorexia and nausea frequently accompany abdominal pain, vomiting may occur but rarely occurs before the onset of pain.

During the evaluation of the patient, emphasis should be placed on the location of the pain and the classic signs. Taking into account that the positivity or negativity of these depends largely on the variants in the location of the appendix as well as the time that has elapsed since the onset of pain ${ }^{(9)}$.

Temperature is a poor predictor of appendicitis, however the presence of marked fever and tachycardia warn of the possibility of perforation and formation of an intra-abdominal abscess ${ }^{1} \mathrm{At}$ this point, it is important to discuss the use of analgesia in patients who are under observation for abdominal pain, especially in those who still do not have a definitive diagnosis and in whom the need for surgery has not yet been ruled out. Classically it has been described that the use of analgesics can attenuate or even abolish the signs suggestive of acute appendicitis, so they should not be administered to these patients. However current evidence does not support this judgment ${ }^{(11)}$. It should be taken into account that there are drugs with pure analgesic properties (opioids), as well as others that additionally have anti-inflammatory mechanisms of action (such as the case of non-steroidal anti-inflammatory drugs), a case-control study carried out by Frei and colleagues showed that opioids are not associated with treatment delay, on the other hand anti-inflammatory drugs did show an association with treatment delay ${ }^{(12)}$.

Radiologic: Plain abdominal radiography should not be used routinely, but it can be useful in cases of atypical symptoms and diagnostic doubt, it can show a fecalith, a localized ileus, loss of the fatty pattern of the peritoneum or unsuspected pneumonia. Pneumoperitoneum only occurs in $1-2 \%$ of appendicitis cases ${ }^{(9)}$.

Ultrasound (US) and abdominal tomography (CT) have been compared in recent years in order to refine the diagnosis of acute appendicitis ${ }^{(13)}$. CT has shown a sensitivity and specificity of $94 \%$ and $95 \%$ in children, respectively, and $94 \%$ and $94 \%$ in adults. In the same study, US showed a sensitivity and specificity of $88 \%$ and $94 \%$ in children respectively, and of $83 \%$ and $93 \%$ in adults ${ }^{(14)}$.

Another disadvantage of US is its known dependence on the knowledge, skill, and patience of the sonographer who performs and interprets it ${ }^{(15)}$.

Some authors have promoted the protocol use of CT in patients who meet the criteria for suspicion of acute appendicitis since their admission, as they have shown a reduction in hospitalization costs and better results in these patients ${ }^{(13)}$. 
Since CT use has become more popular in the United States, rates of negative appendectomies have decreased. However, no improvement has been shown in patients with classic appendicitis symptoms ${ }^{(16,17)}$.

Carrying out a CT scan unnecessarily delays the diagnosis and treatment, which is why it is concluded that it is preferable to carry out the study in cases where there is diagnostic doubt ${ }^{(18)}$.

Laboratory: Most patients have a blood count prior to surgery as part of the basic studies; leukocytosis between 12,000 and $18,000 \mathrm{~mm} 3$ is very frequently observed. ${ }^{(34)}$ The leukocyte count can be useful in the diagnosis and in the exclusion of appendicitis, but it has no value in the differentiation between complicated and uncomplicated appendicitis.. ${ }^{(35)}$

Urinalysis is usually requested to exclude the possibility of urinary tract infection when it is suspected, and pyuria and/or hematuria without bacteriuria may be found in one third of patients with appendicitis due to the proximity of the ureter and the bladder.. ${ }^{(36)}$

Differential Diagnosis: The differential diagnosis of acute appendicitis could involve any entity that causes abdominal pain, however there are some pathologies that are more commonly confused.

Aim of the study: To Compare between Alvarado scoring system and Ohman score as a diagnostic tool for acute appendicitis

\section{Patients and Method}

A prospective cross-sectional study carried at AlYarmouk Teaching hospital and Baghdad Teaching hospital at the period from the first of Jan 2020 to end of July 2020, in which 190 patients from both genders were enrolled, and their ages ranged from 12-68 years.

Statistical Analysis: SPSS version 26 (Statistical Package for the Social Sciences) used for entry and analysis of data. Results existing in the form of tables and graphs. Chi square test used to assess association between descriptive data and Fisher exact test used if the chi square test is not applicable. $\mathrm{P}$ value $<0.05$ will be considered significant.

\section{Results}

The current study was included 190 patients with suspected appendicitis, with in a mean age $(27.4 \pm 0.8)$ year and the main age group was in group between (10-19) years old, female (57.6\%) was more than male $(42.4 \%)$, and the female mean age was $(25.4 \pm 7.2)$ years which is younger than male mean age $(27.5 \pm 3.1)$ years.

Table 1 revealed that time needed from the beginning of the clinical presentation until the time of operation was mainly in group of time $<24$ hours, then patient's in-group between 24-48 hours, and patients needed more than 2 days ( $>48$ hours) with the majorities of female group $(79.5 \%)$.

Table 1: Time needed until operation

\begin{tabular}{|l|l|c|c|c|c|c|c|}
\hline \multirow{2}{*}{ Variable } & \multicolumn{2}{|c|}{ Male } & \multicolumn{2}{c|}{ Female } & \multicolumn{2}{c|}{ Total } \\
\cline { 3 - 8 } & $\mathbf{N o}$ & $\mathbf{\%}$ & No. & $\mathbf{\%}$ & No. & \% \\
\hline \multirow{3}{*}{$\begin{array}{l}\text { Duration } \\
\text { (hours) }\end{array}$} & 24 & 52 & 69.3 & 23 & 30.7 & 75 & 100.0 \\
\cline { 2 - 8 } & $24-48$ & 22 & 52.4 & 20 & 47.6 & 42 & 100.0 \\
\cline { 2 - 8 } & $>48$ & 15 & 20.5 & 58 & 79.5 & 73 & 100.0 \\
\hline \multicolumn{2}{|l|}{ Total } & 89 & 46.8 & 101 & 53.2 & 190 & 100.0 \\
\hline
\end{tabular}

As for the validity test of the AS to diagnosis of the acute appendicitis we found that from those in group I (Alvarado score $\geq 7$ ) 114/120 patients were truly positive diagnosed with the disease while $6 / 120$ were false positive. For group II (Alvarado score $<7$ ) we found that $12 / 40$ were diagnosed as false negative and $28 / 40$ patients were diagnosed as true negative. 
Table 2: Validity test of Alvarado group

\begin{tabular}{|l|c|c|c|c|}
\hline AS group & No. & Confirmed Appendicitis & Not Appendicitis & P value \\
\hline Group I (Alvarado score $\geq 7)$ & 135 & (True positive) 122 & (False positive) 13 & 0.001 \\
\hline Group II (Alvarado score $<7$ ) & 55 & (False negative) 17 & (True negative) 38 & Hs \\
\hline Total & $\mathbf{1 9 0}$ & $\mathbf{1 3 9}$ & $\mathbf{5 1}$ & \\
\hline
\end{tabular}

Hs: Highly significant difference

Regarding to the validity test of the Ohmann score to diagnosis of the acute appendicitis we found that from those in group I $(\geq 12)$ about $143 / 148$ patients were truly positive diagnosed with the disease while $5 / 148$ were false positive (patients don't have the appendicitis but we diagnosed it as app). As for group II (score <12) we found that $60 / 82$ were diagnosed as false negative and $22 / 82$ patients were diagnosed as true negative. (Table 3).

Table 3: Validity test of Ohmann group

\begin{tabular}{|l|c|c|c|c|}
\hline Ohmann group & No. & Confirmed Appendicitis & Not Appendicitis & P value \\
\hline Group I $(\geq 12)$ & 117 & (True positive) 105 & (False positive) 13 & $<0.001$ \\
\hline Group II $($ score $<12)$ & 73 & (False negative) 50 & (True negative) 23 & $\mathbf{3 5}$ \\
\hline Total & $\mathbf{1 6 0}$ & $\mathbf{1 5 5}$ & \\
\hline
\end{tabular}

Table 4 show the accuracy of the test to detect the acute appendicitis: for the Ohman score we found that the sensitivity was $(68 \%)$, specificity was $(64 \%)$ accuracy $(67 \%)$, positive predictive value $(89 \%)$, negative predictive value (32\%). While for AS the sensitivity was (88\%), specificity was $(75 \%)$ accuracy $(84 \%)$, positive predictive value $(90 \%)$, negative predictive value $(60 \%)$.

Table 4: Accuracy of the test

\begin{tabular}{|l|c|c|}
\hline & Ohmann score & AS \\
\hline Sensitivity & 68 & 88 \\
\hline Specificity & 64 & 75 \\
\hline Accuracy & 67 & 84 \\
\hline PPV & 89 & 90 \\
\hline NPV & 32 & 69 \\
\hline
\end{tabular}

\section{Discussion}

The current study shows that incidence of acute appendicitis was more common in youthful group with more prominent in female than male. which is in contract with greatest of the outcomes of regular world's studies, and recognized that it happened mostly in young population. Which is same that stated by American studies approved by Abdeldaim Y et al, ${ }^{(19)}$. A number of scoring systems that have been developed for the perseverance of rising the validity of both the sensitivity and specificity of the diagnosis of acute appendicitis had been frequently tested. Scoring systems signify low-cost, non-invasive and easy to use diagnostic benefit ${ }^{(20)}$. As for Ohmann scoring system, the study done by Koppad SN et al, specified that Sensitivity of $96 \%$, specificity $66.7 \%$, positive predictive value $82.8 \%$ and negative predictive value of $90.9 \%$. (21) Moreover, in a study carried by Memon ZAetal, found that sensitivity (92.3\%) and specificity $(80.6 \%)$, positive predictive value was $(92.3 \%)$ and negative predictive values $(83.3 \%)$. ${ }^{(22)}$

in the present study we found that the validity test at Alvarado score cutoff value of (7) was as follow: sensitivity (88\%), specificity was (75\%), accuracy (84\%), positive predictive value $(90 \%)$, negative predictive value $(69 \%)$. Xingye $\mathrm{W}$ et al, found that Alvarado score established the highest sensitivity (92.7\%) percentage. ${ }^{(23)}$ In Agbo S et al, study in the same cut-off of the Alvarado scores found that validity test was butter than that in our study. ${ }^{(24)}$

Memon et al, study found that the sensitivity of this scoring system (Alvarado) has a sensitivity of $93.5 \%$, specificity of $80.6 \%$, PPV of $92.3 \%$, NPV of $83.3 \%$, and accuracy of $89.8 \% .{ }^{(22)}$ While in Tekeli MT et al, study 
the sensitivity was $(75.2 \%)$, specificity was $(76.1 \%)$ PPV (90.2\%), NPV (50.9\%) and accuracy of the test to diagnose the disease was $(75.4 \%){ }^{(25)}$

\section{Conclusion}

Alvarado score was better than Ohmann score in diagnosis of the patients with acute.

\section{Conflicts of Interest: No}

\section{Source of Funding: Self}

Ethical Clearance: Was taken from the scientific committee of the Iraqi Ministry of health

\section{References}

1. Fitz, RH. Perforating inflammation of the vermiform appendix: With special reference to its early diagnosis and treatment. Trans Assoc Am Phys, 1886;1:107-143.

2. Rutkow IM. Appendicitis: The quintessential American surgical disease. Archives of Surgery. 1998 Sep 1;133(9):1024-24.

3. Davies GM, Dasbach EJ, Teutsch S. The burden of appendicitis-related hospitalizations in the United States in 1997. Surgical infections. 2004 Jun 1;5(2):160-5.

4. Addiss DG, Shaffer N, Fowler BS, Tauxe RV. The epidemiology of appendicitis and appendectomy in the United States. American journal of epidemiology. 1990 Nov 1;132(5):910-25.

5. Temple CL, Huchcroft SA, Temple WJ. The natural history of appendicitis in adults. A prospective study. Annals of surgery. 1995 Mar;221(3):278.

6. Kyriazis AA. Development of lymphoid tissues in the human embryo and early fetus. Arch Pathol. 1970;90:348-53.

7. Schumpelick V, Dreuw B, Ophoff K, Prescher A. Appendix and cecum: embryology, anatomy, and surgical applications. Surgical Clinics. 2000 Feb 1;80(1):295-318.

8. Birnbaum BA, Wilson SR. Appendicitis at the millennium. Radiology. 2000 May;215(2):337-48.

9. Dominguez EP, Sweeney JF, Choi YU. Diagnosis and management of diverticulitis and appendicitis. Gastroenterology Clinics. 2006 Jun 1;35(2):36791.

10. Dominguez EP, Sweeney JF, Choi YU. Diagnosis and management of diverticulitis and appendicitis. Gastroenterology Clinics. 2006 Jun 1;35(2):36791.

11. Pace $\mathrm{S}$, Burke TE. Intravenous morphine for early pain relief in patients with acute abdominal pain. Academic emergency medicine. 1996 Dec;3(12):1086-92.

12. Frei SP, Bond WF, Bazuro RK, Richardson DM, Sierzega GM, Wasser TE. Is early analgesia associated with delayed treatment of appendicitis? The American journal of emergency medicine. 2008 Feb 1;26(2):176-80.

13. Rao PM, Rhea JT, Novelline RA, Mostafavi AA, McCabe CJ. Effect of computed tomography of the appendix on treatment of patients and use of hospital resources. New England Journal of Medicine. 1998 Jan 15;338(3):141-6.

14. Doria AS, Moineddin R, Kellenberger CJ, Epelman M, Beyene J, Schuh S, Babyn PS, Dick PT. US or CT for diagnosis of appendicitis in children and adults? A meta-analysis. Radiology. 2006 Oct;241(1):83-94.

15. Lee JH, Jeong YK, Hwang JC, Ham SY, Yang SO. Graded compression sonography with adjuvant use of a posterior manual compression technique in the sonographic diagnosis of acute appendicitis. American Journal of Roentgenology. 2002 Apr;178(4):863-8.

16. Flum DR, Morris A, Koepsell T, Dellinger EP. Has misdiagnosis of appendicitis decreased over time?: a population-based analysis. Jama. 2001 Oct 10;286(14):1748-53.

17. Lee SL, Walsh AJ, Ho HS. Computed tomography and ultrasonography do not improve and may delay the diagnosis and treatment of acute appendicitis. Archives of surgery. 2001 May 1;136(5):556-62.

18. Garfield JL, Birkhahn RH, Gaeta TJ, Briggs WM. Diagnostic pathways and delays on route to operative intervention in acute appendicitis. The American Surgeon. 2004 Nov 1;70(11):1010.

19. Abdeldaim Y, Mahmood S, Mc Avinchey D: The Alvarado score as a tool for diagnosis of acute appendicitis. Ir Med J 2007, 100:342.

20. UnalOzdemir Z, Ozdemir H, Sunamak O, Akyuz C, Torun M. Comparison of the reliability of scoring systems in the light of histopathological results in the diagnosis of acute appendicitis. Hong Kong Journal of Emergency Medicine. 2019 
Nov;26(6):323-7.

21. Koppad SN, Vandakudri AB, Desai M, Kodliwadmath H. Evaluation of Ohmann score and correlation with ultrasound for diagnosing acute appendicitis. Journal of Surgical Sciences Vol. 2016 Apr;3(2)

22. Memon ZA, Irfan S, Fatima K, Iqbal MS, Sami W., Acute appendicitis: diagnostic accuracy of Alvarado scoring system. Asian J Surg. 2013 Oct;36(4):144-9.

23. Xingye W, Yuqiang L, Rong W, Hongyu Z. Evaluation of diagnostic scores for acute appendicitis. J Coll Physicians Surg Pak. 2018 Feb 1;28(2):110-4.

24. Agbo S, Lawal A, Usman B. Correlation of Alvarado Score and Intra-operative Findings in patients presenting to a tertiary Center in Northwestern Nigeria. Journal of Dental and Medical Sciences 2018; 17(19): 85-93

25. Tekeli MT, Ilhan E, Ureyen O, Senlikci A, Yeldan E, Ozturk M, et al. How much Reliable Is Alvarado Scoring System in Reducing Negative Appendectomy?. Indian Journal of Surgery. 2017 Apr 1;79(2):106-10. 